\title{
Causes of late onset epilepsy in Saudi Arabia: the role of cerebral granuloma
}

\author{
BASIM A YAQUB, CHRYSOSTOMOS P PANAYIOTOPOULOS, \\ MANSOUR AL-NOZHA, WAJDI QTEISHAT, ABDULLAH AL-DALAAN \\ From the Division of Neurology, King Khalid University Hospital, King Saud University, Riyadh, Saudi Arabia
}

SUMMARY Cerebral granulomas, due to infections, have been rarely reported as a cause of late onset epilepsy. The incidence of cerebral granulomas was $7 \%$ in this prospective study of 56 consecutive patients with onset of seizures after the age of 20 years. Other main causes included cerebral tumours $(20 \%)$, arteriovenous malformations $(5 \%)$ and cerebrovascular disease (15\% amongst patients with onset of seizures above the age of 40 years). The incidence of structural abnormalities was higher with increasing age at the onset of seizures and declined with long duration of history of epilepsy. Simple partial seizures were strongly associated with structural abnormalities $(86 \%)$ as opposed to complex partial (33\%) and generalised tonic-clonic seizures $(33 \%)$.

Epileptic seizures starting after the age of 20 years are relatively common ${ }^{1}$ and may be symptomatic of structural cerebral lesions, some of which may be treated and cured. Seizures before the age of 20 are rarely associated with tumours. ${ }^{2}$ If all age groups are considered, $4-12 \%$ of patients with seizures harbour neoplasms. The role of cerebral vascular disease in late onset epilepsy has been recently illuminated. ${ }^{3}$ The value of computed tomographic scan (CT) as a routine investigation in epileptics without focal, clinical or electroencephalographic (EEG) abnormalities has been questioned. ${ }^{4}$ Furthermore, a causative relationship between late onset epilepsy and cerebral granulomas due to infections, has been totally neglected even in old reports from developed countries when infectious diseases and particularly tuberculosis were abundant.

The present prospective study was to determine the causes of late onset epilepsy in Saudi Arabia and to identify patients who are at a "high risk" of suffering from structural cerebral lesions.

Address for reprint requests: Basim Yaqub, Neurology Division, Department of Internal Medicine-38 King Khalid University Hospital, PO Box 2925, Riyadh 11461, Saudi Arabia.

Received 8 November 1985.

Accepted 5 January 1986

\section{Patients and methods}

All new patients, referred for a neurological consultation in King Khalid University Hospital (KKUH) over a 14 month period (December 1983-January 1985) with one or more unequivocal epileptic seizures commencing after the age of 20 years, were evaluated prospectively. Patients with mental retardation, neurological deficits or systemic disorders associated with seizures were excluded. All patients had CT of the brain with and without contrast; it was "blindly" reported by three of us (CPP, WQ, and BY). EEG was recorded in all but four of them and "blindly" reported by two of us (CPP and BY).

\section{Results}

Fifty-six patients were selected who fulfilled the criteria of late onset epilepsy as the only presenting symptom. Thirty-eight $(68 \%)$ were male and $43(77 \%)$ of the patients were Saudi. The CT scan was abnormal in $26(46 \%)$ of the patients. Abnormalities and age distribution are shown in table 1.

Eleven patients had CT scan abnormalities consistent with neoplasms, nine of which were histologically verified and showed: five gliomas (three of low grade and two of high grade), three meningiomas and one brain metastasis from an anaplastic thyroid carcinoma. The CT scan of the remaining two patients was in favour of a meningioma and a low grade gli- 
Table 1 CT scan abnormalities in different age groups

\begin{tabular}{|c|c|c|c|c|c|c|c|c|c|c|c|c|c|}
\hline \multirow[b]{2}{*}{ Age group (yr) } & \multirow{2}{*}{$\begin{array}{l}\text { Total No of } \\
\text { patients }\end{array}$} & \multicolumn{2}{|c|}{$\begin{array}{l}C T \text { scan } \\
\text { abnormalities }\end{array}$} & \multicolumn{2}{|c|}{ Tumours } & \multicolumn{2}{|c|}{$\begin{array}{l}\text { Cerebral granulomas } \\
\text { (Infection) }\end{array}$} & \multicolumn{2}{|c|}{$A V M$} & \multicolumn{2}{|c|}{ Cerebral infarcts } & \multicolumn{2}{|c|}{$\begin{array}{l}\text { Other miscellaneous } \\
\text { lesions }\end{array}$} \\
\hline & & No & $\%$ & No & $\%$ & No & $\%$ & No & $\%$ & No & $\%$ & No & $\%$ \\
\hline $\begin{array}{l}\text { (A) } 20-30 \\
\text { (B) } 31-40 \\
\text { (C) } 41-50 \\
\text { (D) Older than } 50 \\
\text { Total }\end{array}$ & $\begin{array}{r}33 \\
10 \\
6 \\
7 \\
56\end{array}$ & $\begin{array}{r}9 \\
6 \\
5 \\
6 \\
26\end{array}$ & $\begin{array}{l}27 \% \\
60 \% \\
83 \% \\
86 \% \\
46 \%\end{array}$ & $\begin{array}{r}3 \\
3 \\
3 \\
2 \\
11\end{array}$ & $\begin{array}{r}9 \% \\
30 \% \\
50 \% \\
28 \% \\
20 \%\end{array}$ & $\begin{array}{l}1 \\
1 \\
\frac{2}{4}\end{array}$ & $\begin{array}{r}3 \% \\
10 \% \\
33 \% \\
-7 \%\end{array}$ & $\begin{array}{l}2 \\
\frac{1}{3}\end{array}$ & $\begin{array}{l}6 \% \\
10 \% \\
- \\
5 \%\end{array}$ & $\frac{-}{-}$ & $\begin{array}{r}- \\
\overline{28} \% \\
3 \%\end{array}$ & $\begin{array}{l}2^{a}+1^{b} \\
\frac{1^{a}}{2^{c}} \\
6\end{array}$ & $\begin{array}{l}9 \% \\
10 \% \\
28 \% \\
11 \%\end{array}$ \\
\hline
\end{tabular}

a-Nonprogressive hypodense areas.

b-Porencephalic cyst.

c-Moderate generalised cerebral atrophy.

oma, respectively. Three of the six gliomas were seen in the younger age group A (20-30 years old). Meningiomas were equally divided between groups $\mathbf{B}$ and $\mathbf{C}$ (30-50 years old). The only case of brain metastasis was seen in group D (above 50 years old).

Cerebral granulomas, due to infection, were detected in four patients equally divided between all age groups. In two of these the diagnosis of tuberculoma was histologically established, one with multiple lesions and the other with a single cerebral lesion. There was no evidence of extracranial tuberculosis. The third patient showed CT scan abnormalities compatible with calcified tuberculoma and had active tuberculous lymphadenitis. The remaining patient, with a fatal outcome, had multiple cerebral granulomas due to pheohyphomycosis, a species of Claudosporium, as shown by histology.

Arteriovenous malformations (AVM) were found in three patients in the young age groups $A$ and $B$ (20-40 years old). This was confirmed by arteriography in one patient. The second patient had an intracerebral haematoma which subsequently resolved but the last patient refused angiography.

Cerebrovascular disease was evident in the CT scan of two patients in the oldest age group D (older than 50 years), both of which showed multiple infarcts and were also investigated with arteriography and digital subtraction angiography, respectively.

Three patients showed hypodense areas with surrounding volume loss probably related to old vascular insults or trauma. The remaining three patients showed CT abnormalities of a porencephalic cyst in one, and evidence of generalised moderate cerebral atrophy in two patients of the oldest age, above the age of 50 years (table 1).

The incidence of structural abnormalities increased with increasing age of the onset of seizures (table 1) and declined with long duration of history of seizures (table 2).

In all patients with potentially treatable causes (cerebral granuloma, AVM and neoplasms), the
Table 2 Classification and duration of seizures in patients with CT scan abnormalities

\begin{tabular}{|c|c|c|c|}
\hline \multirow[b]{2}{*}{ Duration } & \multirow[b]{2}{*}{ Total } & \multicolumn{2}{|c|}{ Abnormality } \\
\hline & & No & $\%$ \\
\hline \multirow[t]{3}{*}{$\begin{array}{l}\text { Less than } 1 \text { year } \\
1-3 \text { years } \\
3-5 \text { years } \\
\text { More than } 5 \text { years } \\
\text { Total }\end{array}$} & $\begin{array}{r}22 \\
12 \\
9 \\
13 \\
56\end{array}$ & $\begin{array}{r}14 \\
8 \\
2 \\
2 \\
26\end{array}$ & $\begin{array}{l}64 \\
67 \\
27 \\
15 \\
46\end{array}$ \\
\hline & & \multicolumn{2}{|c|}{ CT abnormality } \\
\hline & patients & $N o$ & $\%$ \\
\hline $\begin{array}{l}\text { Generalised tonic-clonic } \\
\text { Complex-partial seizures } \\
\text { Simple partial seizures } \\
\text { Total }\end{array}$ & $\begin{array}{l}24 \\
18 \\
14 \\
56\end{array}$ & $\begin{array}{r}8 \\
6 \\
12 \\
26\end{array}$ & $\begin{array}{l}33 \\
33 \\
86 \\
46\end{array}$ \\
\hline
\end{tabular}

duration of seizures at the time of examination was less than 3 years with two exceptions: one patient with a 4 year history of seizures had histologically confirmed right frontal lobe low grade glioma. The other patient had a 7 year history of seizures with CT scan evidence of right olfactory groove meningioma (she was totally blind from trauma and chickenpox since childhood); she refused operation.

Seizure classification of our patients is shown in table 2. Simple partial seizures were highly related with structural abnormalities $(86 \%)$. Abnormal CT scans were found in only one third of patients with either complex partial seizures or generalised tonicclonic seizures.

EEG was obtained in 52 out of 56 patients. Unequivocal and persistent focal EEG abnormalities were found in 11 patients, $10(91 \%)$ of which showed structural lesions. In 37 patients the EEG showed either generalised abnormalities or insignificant lateralisation; $13(35 \%)$ of which had abnormal CT scans. In only four patients was the EEG entirely normal; they also had normal CT scans. 
It should be emphasized that three patients $(5 \%)$ with potentially treatable conditions (one low grade glioma and two AVM) showed no partial seizures or focal EEG abnormalities.

\section{Discussion}

Our findings of $46 \%$ CT scan abnormalities in late onset epilepsy are comparable to $23-55 \%$ previously reported. ${ }^{4-10}$ The higher incidence of tumours in our patients $(20 \%)$ in comparison to $4-12 \%$ in previous studies ${ }^{13-9}$ might be explained by the fact that the King Khalid University Hospital is one of the main neurological referral centres in Saudi Arabia. Cerebrovascular disease as a cause of seizures was found in two out of 13 patients (15\%) with onset of epilepsy above the age of 40 which is comparable to $18 \%$ recently reported. ${ }^{3}$

Seven percent of our patients showed cerebral granulomas, due to infections, and particularly tuberculomas as a cause of their seizures. This is not reported in other studies and reflects the different pattern of pathology in developing countries. However, it is interesting that granulomas are not included in previous series from the developed countries when tuberculosis was abundant. ${ }^{16}$ In one of our patients with recent occipital partial seizures, four vessels arteriography was entirely normal. CT scan showed multiple intracranial enhancing lesions with surrounding oedema but the ventricles were normal (a pneumoencephalography would therefore be expected to be normal). Histology confirmed tuberculous granuloma. It is therefore possible that cases like this were "missed" in the pre-scan era, and might be increasing in the new series with increasing incidence of tuberculosis in developed countries.

The CT scan abnormalities increased with increasing age at onset of epilepsy and declined with increasing duration of seizures which is in agreement with previous reports. ${ }^{810}$

Simple partial seizures were highly associated with structural abnormalities (86\%) as opposed to complex partial $(33 \%)$ and generalised tonic-clonic seizures $(33 \%)$. Our figures $(86 \%)$ are higher than $48-71 \%$ of previous reports ${ }^{48}$ which may be attri- butable to the prospective nature of our study with particular attention to the recent classification of seizures.

Young $e t a l^{4}$ have questioned the value of CT scan in epileptics without focal, clinical or EEG abnormalities, but their view has been questioned. ${ }^{11}$ Three of our patients $(5 \%)$ with potentially treatable conditions (one with low grade glioma, and two with AVM) failed to show focal clinical features or an EEG pattern of partial seizures and therefore would have escaped correct diagnosis.

The authors are grateful to Professor PK Thomas for reading the manuscript and for advice.

\section{References}

1 Raynor R, Paine R, Carmichael E. Epilepsy of late onset. Neurology 1959;9:111-7.

2 Vignaendra V, NgKK, Lim CL, Loh TL. Clinical and electroencephalic data indicative of brain tumours in a seizures population. Postgrad Med J 1978;54:1-5.

3 Shorvon SD, Gilliatt RW, Cox TCS, Yu Yl. Evidence of vascular disease from CT scanning in late onset epilepsy. J Neurol Neurosurg Psychiatry 1984;47:225-30.

4 Young AC, Borg Constanzi J, Moher PD, St Clair Forbes W. Is routine computerised axial tomography in epilepsy worthwhile? Lancet 1982;ii:1446-47.

5 Bagdanoff BM, Stafford CR, Green L, Gonzales CF. Computerised transaxial tomography in evaluation of patients with focal epilepsy. Neurology 1975; 25:1013-7.

6 Sheehan S. One thousand cases of late onset epilepsy. Irish J Med Sci 1958;6:261-72.

7 Gastaut H, Gastaut JL. Computerised axial tomography in epilepsy. Epilepsia 1976;17:325-36.

8 McGahan JP, Dublin AB, Hill RP. The evaluation of seizure disorders by computerised tomography. J Neurosurg 1979;50:328-32.

9 Fuertein J, Weber M, Kurtz D, Rohmer F. Etude statistique des crises epileptiques apparaissant apres d'age de 60 ans. Sem Hop Paris 1970;46:3115-28.

10 Zimmerman RA, Gonzalez C, Bilaniuk LT, et al. Computed tomography in focal epilepsy. Comput Tomogr 1977;1:83-91.

11 Gilliatt RW, Shorvon SD. Computerised tomography in epilepsy. Lancet 1983;1:293. 